\title{
Solidification modelling
}

\author{
O PRABHAKAR \\ Department of Metallurgical Engineering, Indian Institute of Technology, Madras 600036, \\ India \\ Abstract. The modelling of solidification of a metal/alloy in a mold cavity is increasingly \\ becoming popular with numerous attempts being made to understand the phenomena that \\ occur at the level of the casting (macro level) and that which occur at the microscopic level \\ (micro level). In this paper, an attempt has been made to describe the phenomena occurring \\ at both the macro and the micro levels. \\ At the macro level, the effect of fluid flow on various thermal and solidification parameters \\ has been studied. The results were compared with simulations carried out considering \\ conduction alone and with experimental results. The relative importance of including fluid \\ flow on solidification simulation of a casting has been brought out. \\ At the micro level, an algorithm based on the macro-micro model to take the melt \\ superheat into account while numerically predicting the grain size and dendritic arm spacing \\ at different locations of an $\mathbf{A l}-7 \%$ Si alloy sand casting has been developed. The results are \\ compared with the experimental values.
}

Keywords. Solidification; modelling; fluid flow; microstructure; simulation; aluminium alloys; superheat.

\section{Introduction}

Since the seventies efforts have been made to simulate the casting process. The development of numerical techniques and fast computers has created major avenues for simulating the solidification of a casting. Now, it has become possible to simulate the casting process by solving the energy, momentum and continuity equations and thereby to obtain the velocities of the liquid metal at different locations in the casting along with the temperatures. Ohnaka (1990) has reviewed the applications of solidification modelling to materials development. Campbell (1991) has reviewed the current limitations and future potentials of solidification modelling.

The finite difference method (FDM) and the finite element method (FEM) are approximation procedures for solving differential equations of the boundary and/or the initial-value type in engineering and mathematical physics. The relative advantages, case of operations and accuracies of each of the two techniques are described in detail in the literature (Kannan et al 1990).

\subsection{Fluid flow and heat transfer}

Convective flow and heat transfer during mould filling and solidification have received less attention than conduction in the past because of significant difficulties in the mathematical treatment and the computational costs involved. However, in recent years, the study of fluid flow in the meit and the mushy zone and the study of the effects of fluid flow on the shape of solid/liquid interface have acquired major importance (Jaisuk and Rubinsky 1986). Fluid flow due to natural convection occurs in the 
majority of casting processes where parts of the melt are at a higher temperature due to the non-equilibrium conditions that prevail during solidification. The convective heat transfer can be important for liquid metals (Cole and Bolling 1972) in spite of the low Prandtl number prevailing. Convection within the melt influences the solidification at both the macroscopic and microscopic levels. The convection changes the shape of the isotherms and reduces the temperature gradients in the melt and also affects the macrosegregation (Ramachandran et al 1982).

The fluid flow equations can be solved either by primitive variables or stream function and vorticity formulations. In the present work the primitive variables approach has been used. There are two widely used methodologies in this formulation.

The first method, called the marker and cell method, has been developed by Harlow and Welch (1965). This technique has undergone various simplifications and modifications and the methods are known as SOLA (Hirt et al 1980) and VOF (Hirt and Nichols 1981). Salcudean and Guthrie (1979), Hwang and Stoehr (1983) and Smith and Wilkes (1975) used this technique to model the mould flow.

Another technique is based on the control volume formulations developed by Spalding and Patankar and is given in the book by Patankar (1980). The algorithms are known as SIMPLE and SIMPLER. Variations of these methods have also been developed by different researchers. The mathematical details of these techniques are well documented by Braaten (1985). Comini and Del Giudice (1985) proposed a $k-\delta$ model which has many similarities to the SIMPLE algorithm.

1.1a Solid/liquid interface treatment: During the solidification simulation, the velocity computation has to account for a moving solid/liquid interface. There are two approaches, namely transformation technique and fixed grid methods. The application of the transformation technique is limited in that it can be applied only to a one-dimensional case or to a case where the interface is constrained to traverse primarily along one coordinate direction. Due to this difficulty, fixed grid methods have become popular and are widely applied to solidification problems. Fixed grid methods can be classified into two categories: the D'Arcy source method and the variable viscosity method (Voller et al 1987).

1.1b D'Arcy source method: This method is widely known as the porous media formulation. In the porous media approach, the two phase cells as well as the solid cells are assumed to be a porous medium (Voller et al 1987). The flow in the two phase cells is treated as flow through a porous matrix. For alloy solidification with columnar growth, the treatment accords closely with the physical reality. The solid phase is assumed to be a porous medium with zero permeability, so that the NavierStokes equations can be solved in the entire domain without specifically locating the solid/liquid interface. The flow through the porous media is governed by the D'Arcy law and is expressed as (Voller and Prakash 1987)

$$
u=-\frac{K}{\mu} \nabla p
$$

where $K$ is the permeability and it is a function of $\Delta H(t)$ for pure metal and $f_{l}$ for alloy (and also the morphology of the mushy region in case of alloy solidification). In a numerical model, this behaviour can be simulated by assigning the sources of the 
Navier-Stokes equations, that is $S_{x}$ and $S_{y}$, as (Voller and Prakash 1987)

$$
S_{x}=-R u ; \text { and } S_{y}=-R v .
$$

Voller and Prakash (1987) derived an expression for $R$, which is given by the equation

$$
R=\frac{C_{1}\left(1-f_{l}\right)^{2}}{f_{l}^{3}+C_{2}}
$$

In the solid phase, where $R$ becomes very high, the Navier-Stokes equations will be dominated by the sources and the velocity forced to a very small value. Various permeability functions available in the literature are listed and compared by Daming Xu and Qingchun Li (1990).

1.1c Heat transfer at mould/metal interface: One of the critical problems in the simulation of the gravity die casting process is the determination and modelling of heat transfer at the mould-metal interface, the heat transfer being affected by the introduction of a gap between the metal and the mould as the molten metal shrinks during solidification. Many researchers have attempted to estimate the interface heat transfer resistance experimentally (Narayanaprabhu et al 1989; Srinivasan 1982; Sharma and Prabhakar 1990) and numerically (Samonds et al 1985).

1.1d Latent heat formulations: As the molten metal/alloy solidifies, the latent heat of fusion is evolved between the liquidus and the solidus temperatures and this has to be taken into consideration to model the solidification of castings. Dalhuijsen and Segal (1986) and Voller and Swaminathan (1990) reviewed different approximations applicable to fixed grid methods. A comprehensive review of different approximations is available in the report published by Madhusudana et al (1989).

The latent heat release can be represented in two ways: front tracking and fixed grid methods. In the front tracking method, the solid-liquid interface is tracked continuously and the latent heat is treated as a moving boundary condition. Crivelli and Idelsohn (1986) and Mackinnon and Carey (1987) solved solidification and interface problems by subdividing the finite elements such that the interface coincides with the boundaries of the subelements. The latent heat approximation methods applicable to fixed grid methods can be broadly classified into four types: post iterative methods (Rolph and Bathe 1982), specific heat approximation methods (Morgan et al 1978), enthalpy methods (Dalhuijsen and Segal 1986) and heat generation or direct approximation methods (Bradley and Fung 1990).

\subsection{Microstructure prediction}

The success of a design of any engineering component depends upon the ability to satisfy the requirements in terms of the properties at various locations in the component. In metallic materials, it is well known that the microstructure is a very valid indicator of the mechanical and electrical properties. In order to do this, the microstructure should be known at different parts of the component. Alternatively, the possibility of simulating or predicting the microstructure at different locations in the component enhances the quality of its design and its production.

Extensive research has also been conducted at the microscopic level to understand 
the theory of microstructure formation. Two approaches are emerging for predicting the microstructure formation during solidification: the deterministic approach and the probabilistic approach.

1.2a Deterministic approach: Oldfield (1966) has studied the solidification of cast iron and has obtained relationships for nucleation and growth and propounded a theory of continuous nucleation. Burden and Hunt (1974) have put forth a theoretical model to explain the variation in cellular or dendritic tip temperatures with velocities and temperature gradient. Flood and Hunt (1987) have developed a model to simulate the columnar and equiaxed growth using the finite difference method. Rappaz (1989) and his coworkers have done extensive research on modelling the microstructure formation in solidification processes by taking into consideration the nucleation and growth phenomena and by adopting a dual time-stepping scheme. Stefanescu et al (1990) have developed an instantaneous nucleation model instead of the continuous nucleation adopted by Rappaz and have validated with the cooling curves for $\mathrm{Al}-\mathrm{Si}$ and gray cast iron castings.

1.2b Probabilistic approach: Brown and Spittle (1991) were the first to adapt MonteCarlo procedure previously developed by Grest et al (1986) for the grain growth in solid state transformations to the case of solidification. This method, in spite of being able to predict the microstructure, is devoid of physical background. Zhu and Smith (1992) used a nucleation site distribution to account for the heterogeneous nucleation, but the physical mechanisms of growth were neglected.

Recently, a combination of both the deterministic and the probabilistic approaches has been attempted by Rappaz and Gandin (1993), where the grain density is calculated in the deterministic way using the macro-micro model and the orientation and growth direction chosen randomly using the probabilistic approach. A simplified extension of the originally proposed 2D method in Rappaz and Gandin (1993) to 3D has also been attempted by Gandin et al (1993).

\section{Present work}

At the macro level, the relative importance of including fluid flow in the modelling of solidification of a sand casting especially with reference to the solidification and thermal parameters was studied and the results are reported in this paper. At the micro level, the effect of including the melt superheat on the microstructure of a solidifying casting was also modelled through the deterministic approach for an $\mathrm{Al}-7 \% \mathrm{Si}$ alloy and the results are reported here.

\section{Fluid flow studies}

The energy, momentum and continuity equations with appropriate initial and boundary conditions were solved in the domain by FEM. The details of the method are explained in Comini and Del Giudice (1985). The latent heat evolution was modelled by the modified temperature recovery method. The flow in the mushy region was modelled by a resistance function suggested by Voller et al (1987). The model that was developed 


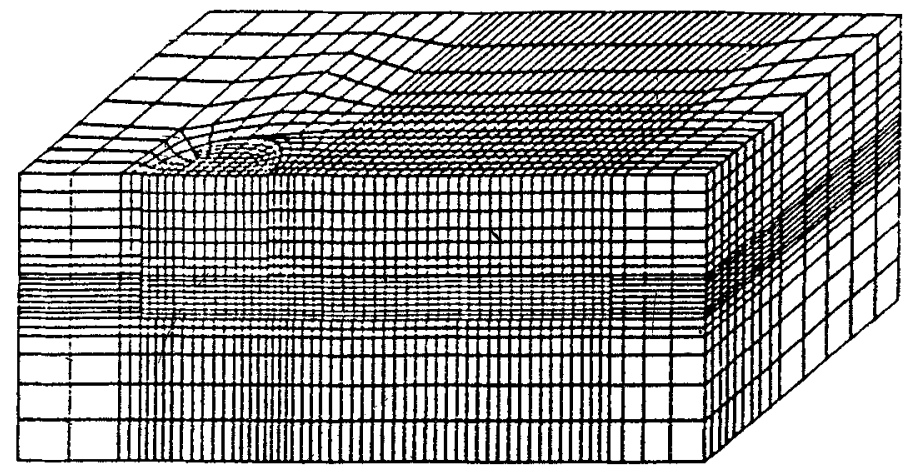

Figure 1. Mesh discretization of plate casting and mould.

was validated (Madhusudana 1993) by solving a thermal cavity problem in two dimensions (Voller and Prakash 1987). The casting and feeder dimensions are $230 \mathrm{~mm} \times$ $150 \mathrm{~mm} \times 36 \mathrm{~mm}$ and $90 \phi \mathrm{mm} \times 120 \mathrm{~mm}$. The feeder is attached to the left end of the plate.

\subsection{Simulation details}

Two simulations were carried out on the solidification of a plate casting: simulation 1 by assuming that the heat transfer in the casting is only by conduction, and simulation 2 by considering the effect of fluid flow on heat transfer.

As the casting is symmetric only one half of the casting and mould was considered for simulation. Three-dimensional analysis was done on this plate casting. The casting and the mould were enmeshed with 14,133 eight-noded isoparametric elements with 16,192 nodes. The discretized mesh is shown in figure 1.

Thirty locations at the centre section of the casting were selected to compare the cooling curves generated by conduction and convection simulations. Six locations at the centre line of the casting corresponding to the thermocouple locations in the experimental setup were chosen. The selected locations in the casting are shown in figure 2. The locations are numbered from left to right in each row.

No under-relaxation parameters were used in the present set of simulations for velocity and pressure corrections. The upwinding method suggested by Hughes (1978) was employed in the present simulation to evaluate the convective terms. A uniform time step value of $5 \mathrm{sec}$ was used for the conduction simulation. The time step was varied from $1 \mathrm{sec}$ at the initial stages to $2 \mathrm{sec}$ towards the end of solidification for the flow and heat transfer simulation. Thermophysical properties used in the simulation are given in table 1 .

In order to compare the experimental and simulation results, experiments were done to determine the cooling curves and the latent heat release rate curve. In this method, change in enthalpy is computed from the solution of energy equation at all the metal nodes undergoing phase change. From the enthalpy-temperature relationship the change in temperature is determined at these nodes. This method was selected as it can be used both for long freezing and short freezing. The initial temperature 


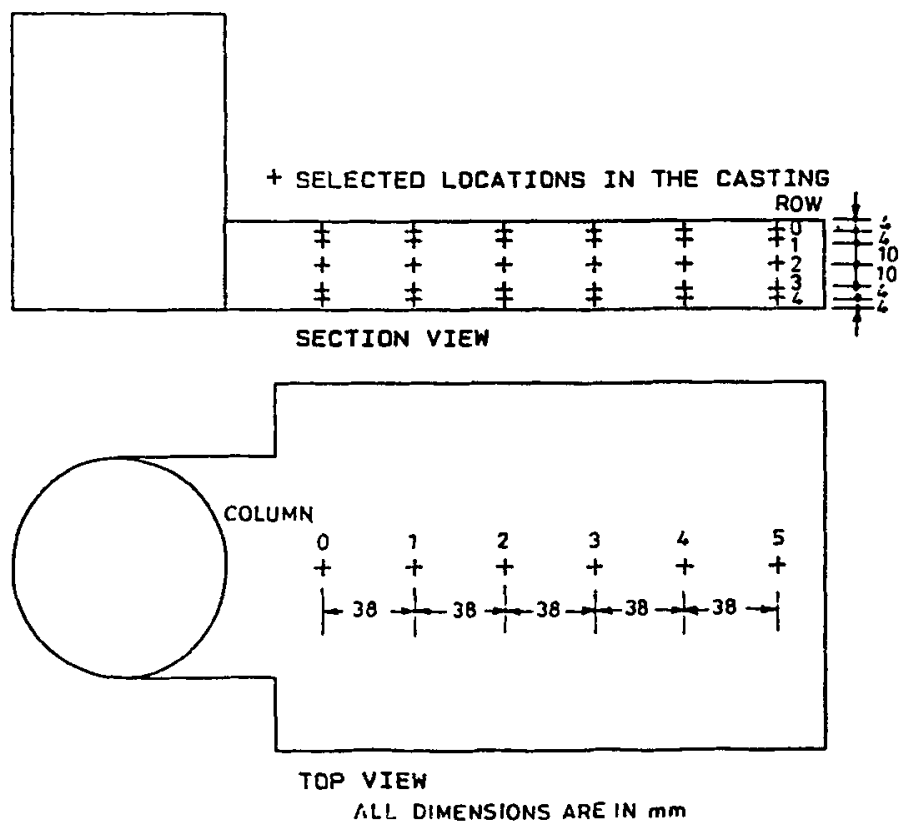

Figure 2. Selected locations in the casting for analysis.

Table 1. Thermophysical properties of $\mathrm{Al}-4 \cdot 5 \% \mathrm{Cu}$ alloy and the moulding sand.

\begin{tabular}{lll} 
& Al-4.5\% Cu alloy & Moulding sand \\
\hline Liquidus temperature & $645^{\circ} \mathrm{C}$ & \\
Solidus temperature & $540^{\circ} \mathrm{C}$ & \\
Thermal conductivity (solid) & $0.453 \mathrm{cal} / \mathrm{cm}-\mathrm{s}-{ }^{\circ} \mathrm{C}$ & $0.0018 \mathrm{cal} / \mathrm{cm}-\mathrm{s}-{ }^{\circ} \mathrm{C}$ \\
Thermal conductivity (liquid) & $0.216 \mathrm{cal} / \mathrm{cm}^{\circ}-{ }^{\circ} \mathrm{C}$ & \\
Density (liquid) & $2.547 \mathrm{~g}^{\circ} \mathrm{cm}^{3}$ & \\
Density (solid) & $2.71 \mathrm{~g} / \mathrm{cm}^{3}$ & $1.58 \mathrm{~g} / \mathrm{cm}^{3}$ \\
Specific heat & $0.26 \mathrm{cal} / \mathrm{g}^{\circ}{ }^{\circ} \mathrm{C}$ & $0.25 \mathrm{cal}^{3} / \mathrm{g}^{\circ} \mathrm{C}$ \\
Thermal expansion coeff. in liquid state & $7.5 \times 10^{-5} /{ }^{\circ} \mathrm{C}$ & \\
Thermal expansion coeff. in mushy region & $6.0 \times 10^{-4} /{ }^{\circ} \mathrm{C}$ & \\
Latent heat & $93.0 \mathrm{cal} / \mathrm{g}$ & \\
Viscosity of liquid & $0.045 \mathrm{~g} / \mathrm{cm}-\mathrm{s}$ & \\
\hline
\end{tabular}

of the molten metal was assumed to be $700^{\circ} \mathrm{C}$ in the present simulation as the maximum temperature recorded by the thermocouples at the end of pouring was $700^{\circ} \mathrm{C}$.

\subsection{Comparison of simulation results}

3.2a Solidification front: The isotherms at different time intervals for the two simulations are shown in figures 3 and 4 . The flow field generated in the casting at $25 \mathrm{sec}$ after pouring is shown in figure 5 . From the figures it can be seen that the convection effects are not high due to the lesser superheat of the liquid metal. The liquidus exit times for six locations in the casting are shown in table 2. Convection 

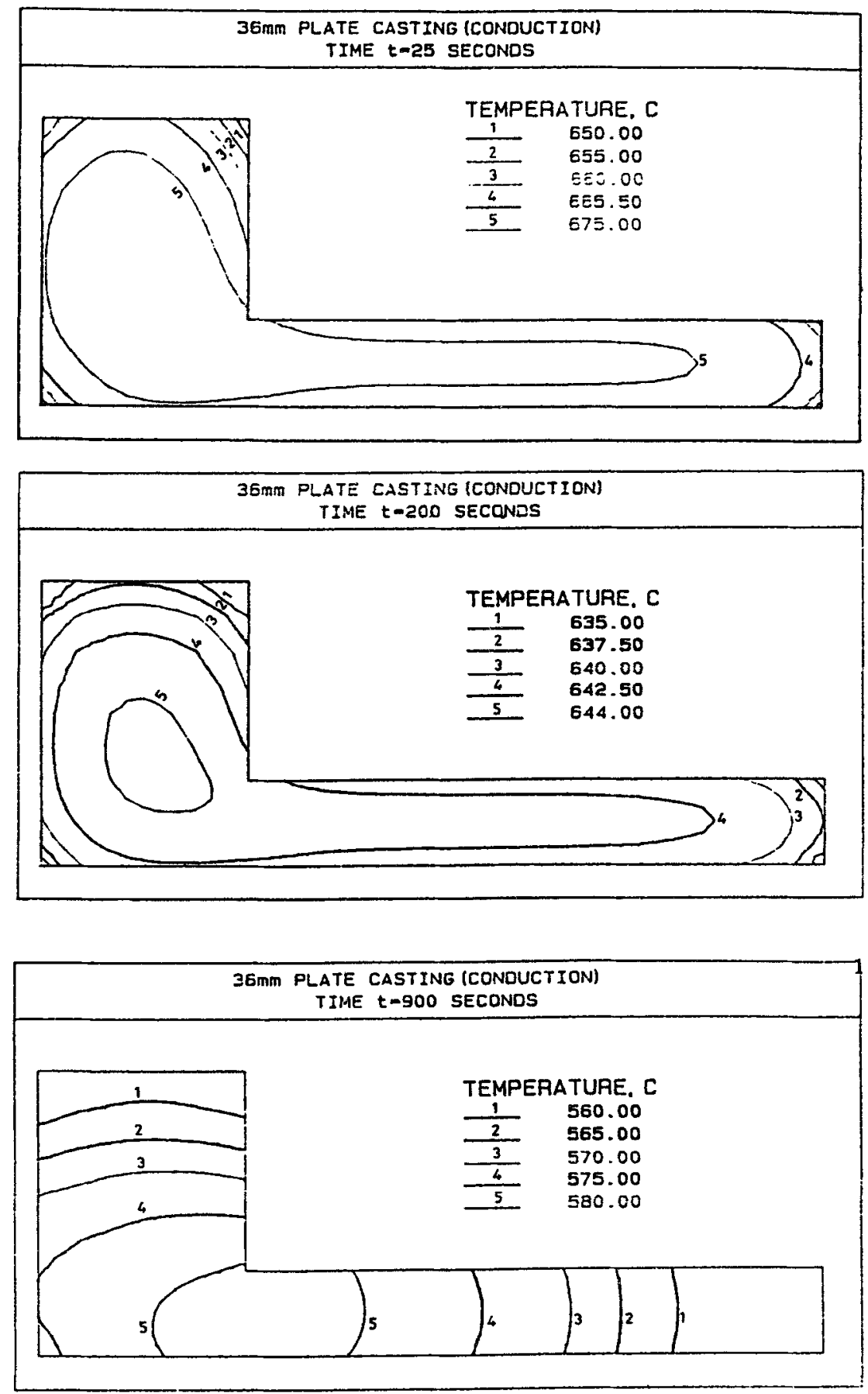

Figure 3. Isotherms from simulation 1 at 25,200 and $900 \mathrm{sec}$. 

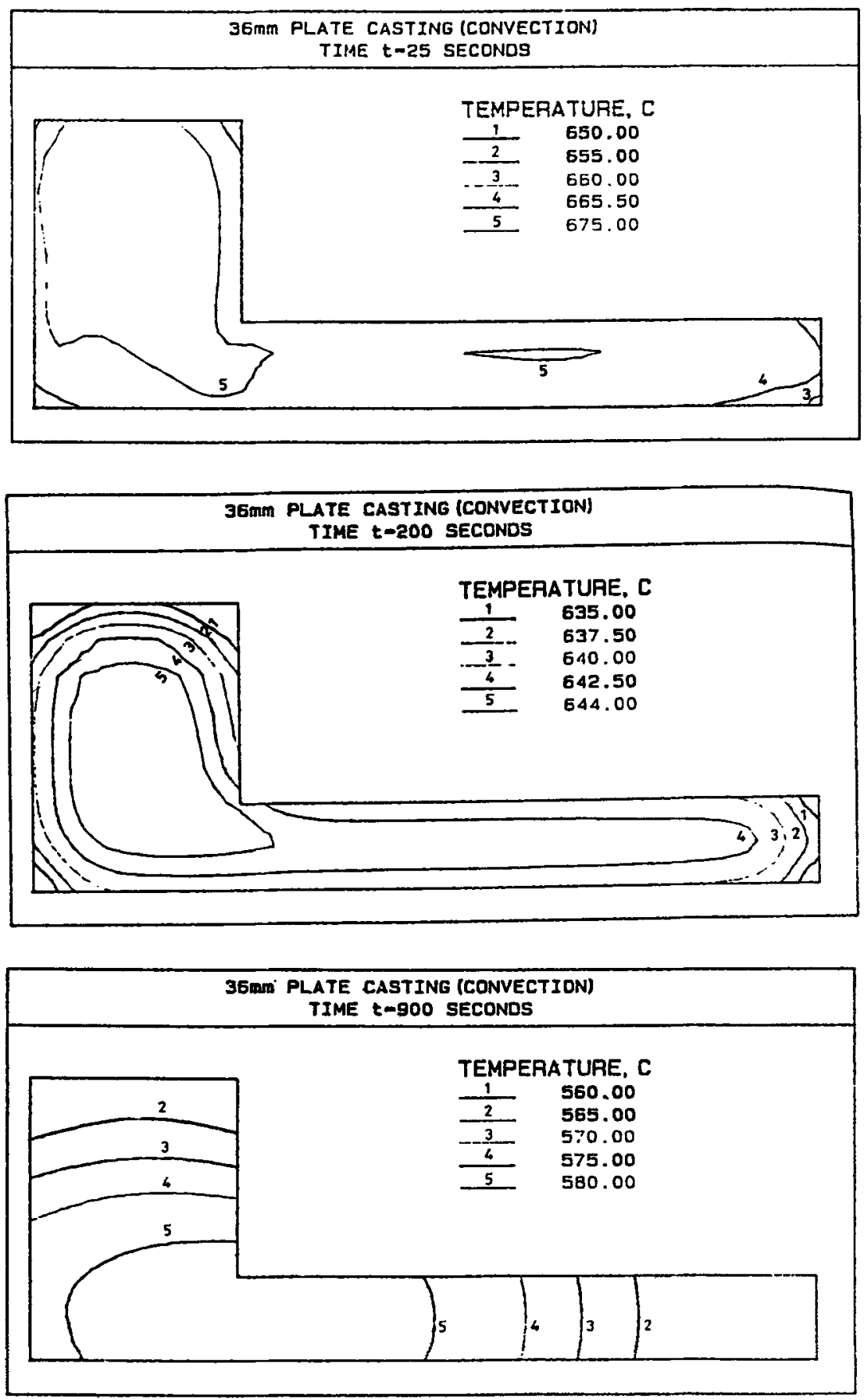

Figure 4. Isotherms from simulation 2 at 25,200 and $900 \mathrm{sec}$. 
Table 2. Comparison of liquidus and solidus exit times (sec).

\begin{tabular}{|c|c|c|c|c|c|c|c|c|c|c|c|c|c|}
\hline \multirow[b]{2}{*}{$\begin{array}{l}\text { Col. } \\
\text { Row }\end{array}$} & \multicolumn{6}{|c|}{ Liquidus exit times } & \multicolumn{6}{|c|}{ Solidus exit times } & \\
\hline & 1 & 2 & 3 & 4 & 5 & 6 & 1 & 2 & 3 & 4 & 5 & 6 & \\
\hline \multirow[t]{3}{*}{2} & 56 & 54 & 50 & 52 & 50 & 48 & 1128 & 1114 & 1102 & 1068 & 1036 & 1000 & experimental \\
\hline & 57 & 57 & 55 & 53 & 51 & 48 & 1126 & 1112 & 1090 & 1062 & 1030 & 995 & convection \\
\hline & 62 & 60 & 60 & 58 & 56 & 50 & 1140 & 1128 & 1106 & 1078 & 1044 & 1010 & conduction \\
\hline
\end{tabular}

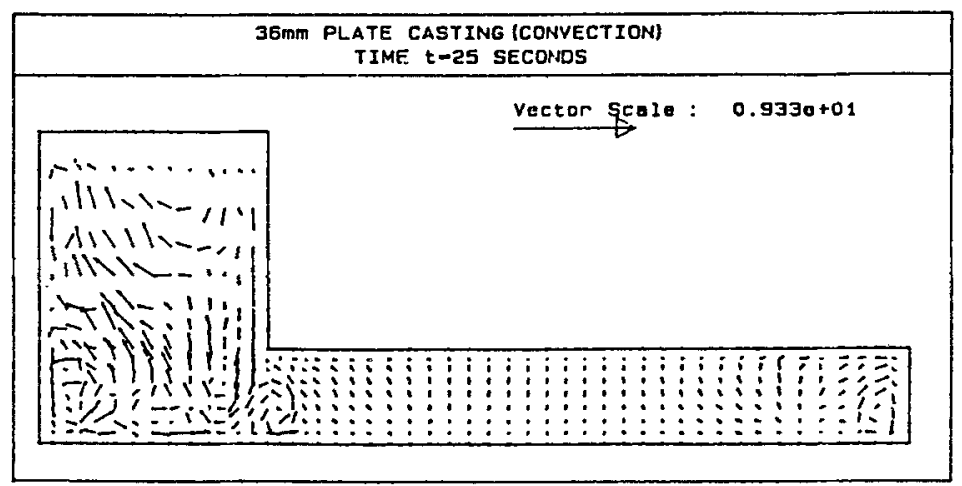

Figure 5. Velocity vectors from simulation 2 at $25 \mathrm{sec}$.

results predict lesser times for liquidus exit compared to the conduction results which confirms the presence of enhanced heat transfer in the liquid state due to convection. The experimentally measured liquidus exit times along with the simulation results are also shown in table 2 . From the table it can be seen that the results predicted by simulation 2 are closer to the experimental values. The time taken for the liquidus isotherm to travel from the 6th location to the 1st location along the centre line of the casting can be computed from table 2 . The value measured by experiments is 8 sec and the one predicted by the convection results is 9 sec and by the conduction results $12 \mathrm{sec}$. Convective heat transfer reduces the deviation from experimental values of the liquidus travel time.

3.2b Cooling curves: The cooling curves from the simulation and experimental results corresponding to locations 1 and 6 are shown in figure 6 . From the curves it is seen that the temperatures simulated by convection fall in between the experimental and conduction results. The conduction results always showed a higher temperature compared to the convection results at any point of time. The shape of the cooling curve replicates the experimentally determined curves shown for all the simulations confirming that the differential thermal analysis indeed gave the latent heat liberation rate nearer to the actual values. The temperature difference between the experimental and simulated results decreased progressively from location 6 to location 1 . This 


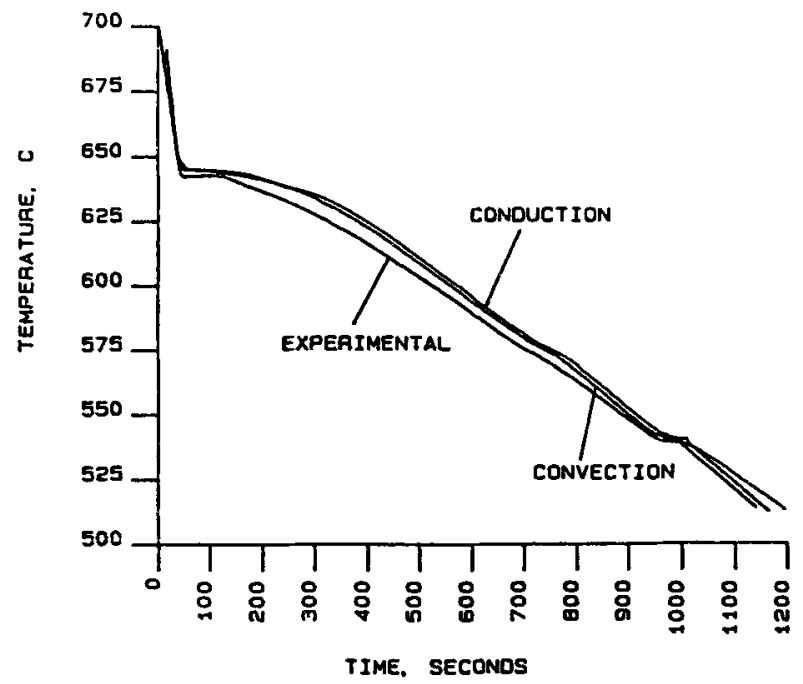

Figure 6. Comparison of experimental and simulated cooling curves; location 6.

difference in deviation can be attributed to the temperature dependence of thermal properties of the moulding sand.

3.2c Solidification times: From the cooling curve data, the solidification times were computed for six locations in the casting. The computed solidification times along with the experimentally determined ones are tabulated in table 2 . From the data it can be seen that the time taken for the solidus isotherm to travel from the 6th thermocouple location to the 1st location predicted by the simulations is nearer to the experimental one. The maximum deviatio. was found to be only $3 \mathrm{sec}$. The maximum deviation in solidification times is also less than $1 \%$.

3.2d Temperature gradients: The temperature gradients at $545^{\circ} \mathrm{C}$ were calculated from the cooling curve data from the simulation results and are shown in table 3 . Temperature gradients calculated from the experimental results along with the simulation results are shown in table 3. From the table it can be seen that the variation of temperature gradient from the free end to the feeder end is more in the conduction $\left(1 \cdot 13^{\circ} \mathrm{C} / \mathrm{cm}\right)$ simulation results compared to the convection $\left(1.02^{\circ} \mathrm{C} / \mathrm{cm}\right)$ results. The

Table 3. Temperature gradients $\left({ }^{\circ} \mathrm{C} / \mathrm{cm}\right)$ along the centre line of the casting.

\begin{tabular}{lllllll}
\hline \multicolumn{6}{c}{ Gradients between thermocouple locations } \\
Row & $1-2$ & $2-3$ & $3-4$ & $4-5$ & $5-6$ & \\
\hline 2 & 0.55 & 1.07 & 0.82 & 1.03 & 1.40 & experimental \\
& 0.52 & 0.97 & 1.36 & 1.56 & 1.54 & convection \\
& 0.46 & 0.94 & 1.34 & 1.59 & 1.59 & conduction \\
\hline
\end{tabular}

Note: The accuracy of the temperature measurements with a 12-bit A/D convertor with $\mathrm{K}$-type thermocouples is $\pm 0-50^{\circ} \mathrm{C}$. 
experimental results show still less variation $\left(0.85^{\circ} \mathrm{C} / \mathrm{cm}\right)$ between locations 3 and 5 . The simulation results do not exhibit the same. The maximum deviation in temperature gradients is $0.14^{\circ} \mathrm{C} / \mathrm{cm}$ and $0.19^{\circ} \mathrm{C} / \mathrm{cm}$ for convection and conduction results respectively. The difference in the deviation is less than the experimental error of $\pm 0 \cdot 16^{\circ} \mathrm{C} / \mathrm{cm}$. (The accuracy of temperature measurements is shown in table 3.)

\section{Summary}

The inclusion of fluid flow in solidification modelling problems increases the accuracy of simulation marginally. However, as most of the convective effects are experienced near the liquidus temperature, the simulation does not give any useful information while evaluating the solidification parameters near the solidus isotherm where the fluid flow is nearly nonexistent.

\section{Microstructure simulation}

In order to predict the microstructure at different locations in a casting, the deterministic approach of macro-micro modelling (Rappaz 1989) was adopted.

The casting along with the mould was solved for the energy equation neglecting the effect of fluid flow macroscopically and the temperatures at different nodes in the domain obtained. Then the model that has been developed (Venkataramani et al 1993) to include the nucleation and growth phenomena similar to the one reported by Rappaz (1989) was used to obtain the details of grain size and dendritic arm spacings. The details of the procedure for macro-micro modelling are reported elsewhere (Venkataramani et al 1993).

Al-7\% Si alloy was poured into a stainless steel mould of the dimensions shown in figure 7 at different extents of superheat with constant furnace holding times of $10 \mathrm{~min}$. The melt was degassed and poured into the mould. One thermocouple was inserted into the molten metal in the mould at a location shown in figure 7 and the temperatures recorded through a data logger.

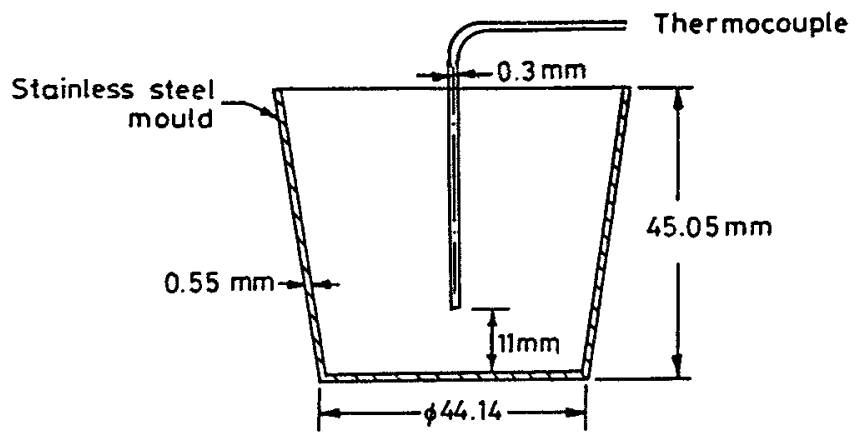

Figure 7. Stainless steel mould showing thermocouple location. 
Table 4. Grain size measurements.

\begin{tabular}{lccccc}
\hline $\begin{array}{l}\text { Pouring } \\
\text { temperature } \\
\left({ }^{\circ} \mathrm{C}\right)\end{array}$ & $\begin{array}{c}\text { Measured } \\
\text { area (mean) } \\
\left(\mathrm{mm}^{2}\right)\end{array}$ & $\begin{array}{c}\text { Standard } \\
\text { deviation } \\
\left(\mathrm{mm}^{2}\right)\end{array}$ & minimum & maximum & $\begin{array}{c}\text { Grain } \\
\text { radius (mm) }\end{array}$ \\
\hline 700 & 0.5445 & 0.3078 & 1.154 & 3.979 & 0.389 \\
800 & 4.209 & 3.021 & 1.175 & 3.654 & 1.08 \\
900 & 42.97 & 18.79 & 1.195 & 3.328 & 3.66 \\
\hline
\end{tabular}

Table 5. Comparison of maximum undercooling and $N_{\max }$ values determined experimentally.

\begin{tabular}{lccc}
\hline & \multicolumn{2}{c}{ Maximum undercooling (K) } & \\
\cline { 2 - 3 } $\begin{array}{l}\text { Pouring } \\
\text { temperature }\left({ }^{\circ} \mathrm{C}\right)\end{array}$ & experimental & simulated & $N_{\max }\left(\mathrm{mm}^{-3}\right)$ \\
\hline 700 & 3.1 & 2.69 & 100 \\
800 & 3.0 & 3.67 & 0.65 \\
900 & 4.5 & 5.54 & 0.01 \\
\hline
\end{tabular}

\subsection{Determination of $N_{\max }$}

The $N_{\max }$ corresponding to each of the pouring temperatures were evaluated experimentally after determining the grain size as shown below.

5.1a Grain size: The grains were observed to be mostly uniform and table 4 shows the mean grain size and the standard deviation as measured through an optical grid analyser. The grid analyser provides data regarding the area of the phase detected, its perimeter, and the standard deviation of the distribution of such phases detected. The grain was assumed to be spherical with the plane surface passing through its centre. The grain radius was then estimated from the average grain area according to the relationship

$$
R_{g}=\left(\frac{\text { Area }}{\pi}\right)^{0.5}
$$

5.1b $N_{\max }$ evaluation: The maximum undercooling $\Delta T_{\mathrm{act}}$ measured from experiments are given in table 5 . The relationship between the number of nuclei present at any location per unit volume and the undercooling is assumed to be gaussian (Rappaz 1989) and hence, knowing the values of $N_{\max }, \Delta T_{\max }$ and $\Delta T_{\sigma}$, the number of nuclei present per unit volume at any undercooling $\Delta T$ can be obtained. Similarly, knowing $\Delta T_{\text {act }}$ and $N_{\text {act }}$, the gaussian was fixed, keeping $\Delta T_{\sigma}$ and $\Delta T_{\max }$ unaltered. $N_{\max }$ thus calculated from each of the three cooling curves corresponding to the three pouring temperatures $700^{\circ} \mathrm{C}, 800^{\circ} \mathrm{C}$ and $900^{\circ} \mathrm{C}$ are also given in table 5 . These values were used for obtaining an expression for $N_{\max }$ as a function of $T_{\text {pour }}$.

The following exponential relationship was fitted for the relationship between $N_{\max }$ 
and $T_{\text {pour }}$ :

$$
N_{\max }=C \exp \left(\frac{D}{T_{\text {pout }}}\right),
$$

where $C$ and $D$ are found out to be $3.47 \times 10^{-4} \mathrm{~mm}^{-3}$ and $52560.14 \mathrm{~K}$ respectively.

\subsection{Comparison of simulated and experimental results}

5.2a Simulation: The castings which were poured to obtain the grain size were also simulated using the macro-micro modelling approach. As the temperature gradients were steeper close to the mould wall, a finer mesh was employed and the mesh was made progressively coarser towards the centre. The mesh was discretized into 810 finite element nodes and 704 elements. Though the problem is three-dimensional in nature, the geometry and the conditions are symmetric about the axis thus enabling it to be treated as a two-dimensional axisymmetric pioblem. For the purpose of simulation, the mould was assumed to be filled instantaneously at the start of solidification and the effect of convection was modelled as an equivalent increase in thermal conductivity of the metal. Though this assumption would lead to a certain degree of inaccuracy, the earlier attempts to study the effect of including fluid flow in the analysis on cooling curves and other macroscopic parameters justify the assumption (section under fluid flow).

The simulation for predicting the grain size using the macro-micro modelling was carried out for the above three castings at three different pouring temperatures $700^{\circ} \mathrm{C}$, $800^{\circ} \mathrm{C}$ and $900^{\circ} \mathrm{C}$, with the corresponding values of $N_{\max }$. The temperature, fraction solid and the grain size data were stored for each timestep. The local solidification

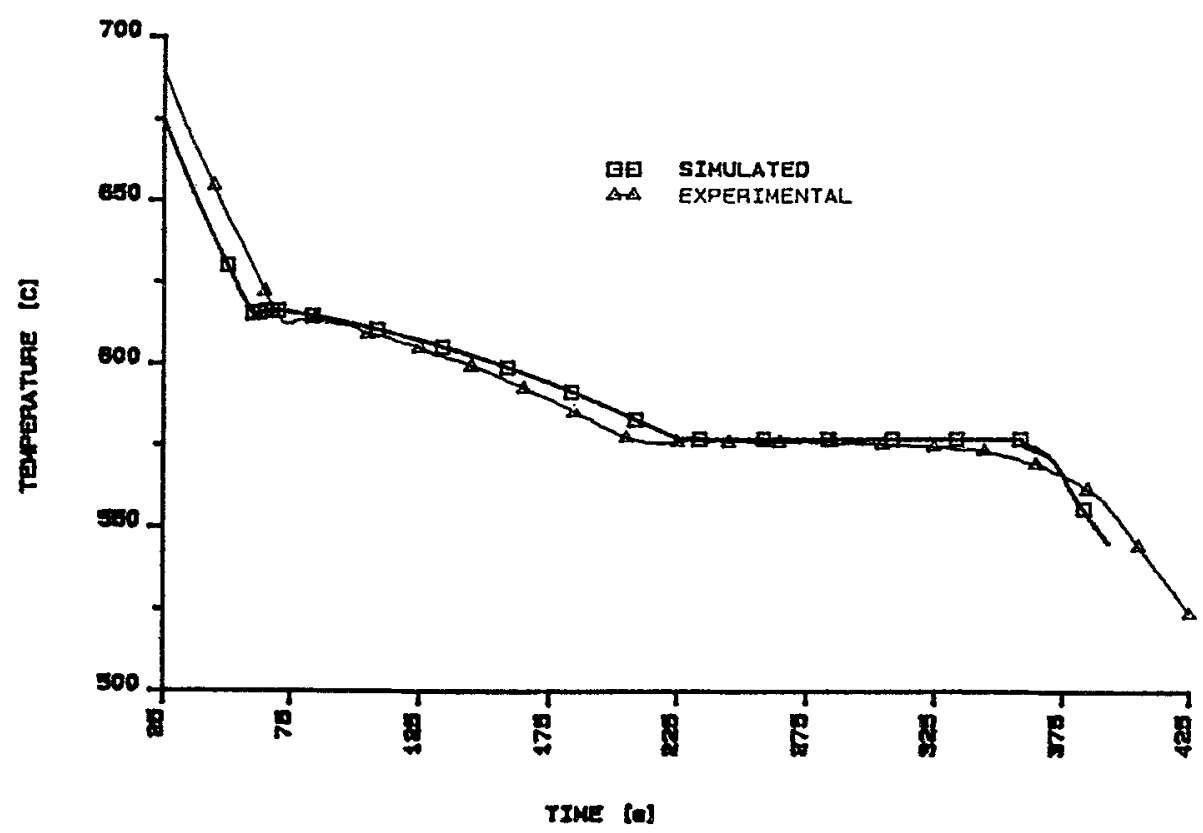

Figure 8. Cooling curves corresponding to a pouring temperature of $700^{\circ} \mathrm{C}$. 
times and the maximum undercoolings were also stored for each node. In addition, temperature, fraction solid, grain size and the number of nuclei per unit volume were stored for specific nodes as functions of time to plot cooling curves.

5.2b Cooling curves: The cooling curves were plotted from the simulation results corresponding to a node coinciding with the thermocouple location. A typical cooling curve is shown in figure 8 corresponding to the pouring temperature of $700^{\circ} \mathrm{C}$. The simulated and the experimental cooling curves can be seen to match reasonably well and the root mean square deviation was found to be $6.04^{\circ} \mathrm{C}, 6.99^{\circ} \mathrm{C}$ and $6.96^{\circ} \mathrm{C}$ corresponding to each of the pouring temperatures, $700^{\circ} \mathrm{C}, 800^{\circ} \mathrm{C}$ and $900^{\circ} \mathrm{C}$, respectively. These values only represent a parallel shift in the curve and in no way represent the accuracy of the undercooling calculations. If the simulated cooling curves are magnified to show the undercooling and recalescence and transposed on the experimental curves, the error is found to be $0.4^{\circ} \mathrm{C}$ for a pouring temperature of $700^{\circ} \mathrm{C}$. So, from the point of view of estimation of the grain size, which is dependent upon the undercooling, the simulation can be taken to be satisfactory.

5.2c Further discussions on grain size: The grain size at any location is known to be entirely controlled by the extent of maximum undercooling. In order to compare the undercooling obtained through simulation with the experimental ones corresponding to the three pouring temperatures $700^{\circ} \mathrm{C}, 800^{\circ} \mathrm{C}$ and $900^{\circ} \mathrm{C}$, the cooling curves are magnified and the portion showing the undercooling and the recalescence for $800^{\circ} \mathrm{C}$ displayed in figure 9 . The maximum undercooling experimentally observed and that predicted were quite close and are as given in table 5.

The contours showing the calculated grain size distribution across the cross section are shown in figures 10 to 12 corresponding to the three pouring temperatures $700^{\circ} \mathrm{C}$, $800^{\circ} \mathrm{C}$ and $900^{\circ} \mathrm{C}$. As can be observed in the figures, the range of grain size values

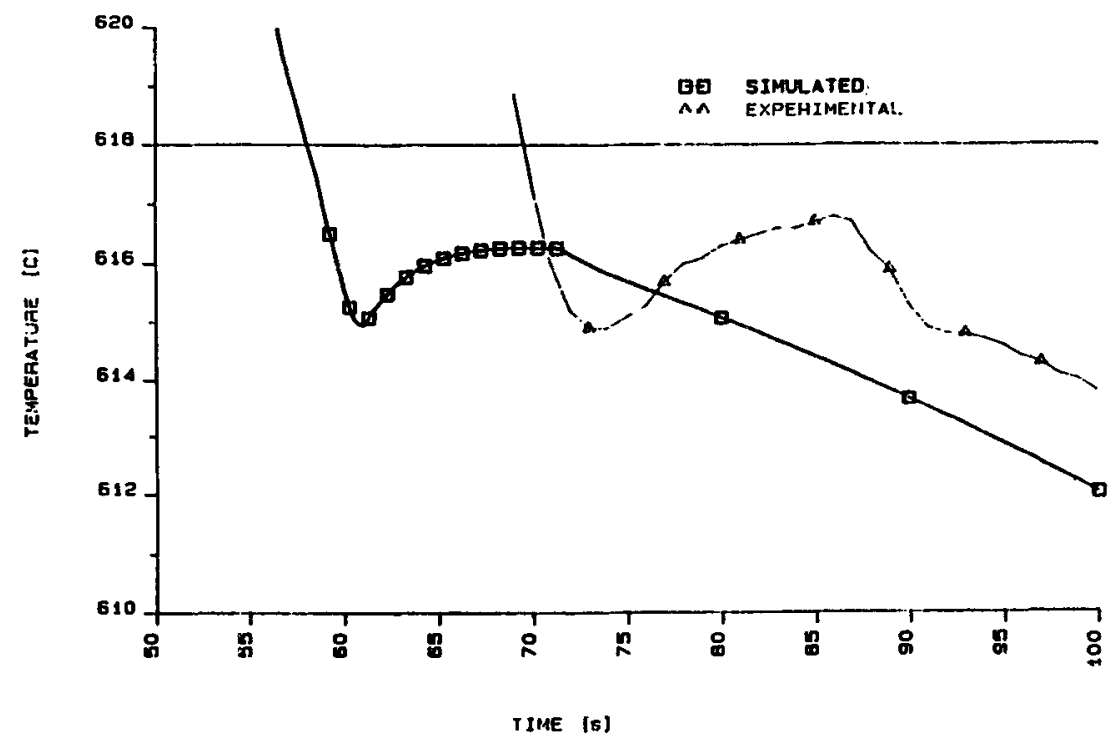

Figure 9. Enlarged portion of cooling curves showing recalescence; pouring temperature = $700^{\circ} \mathrm{C}$. 

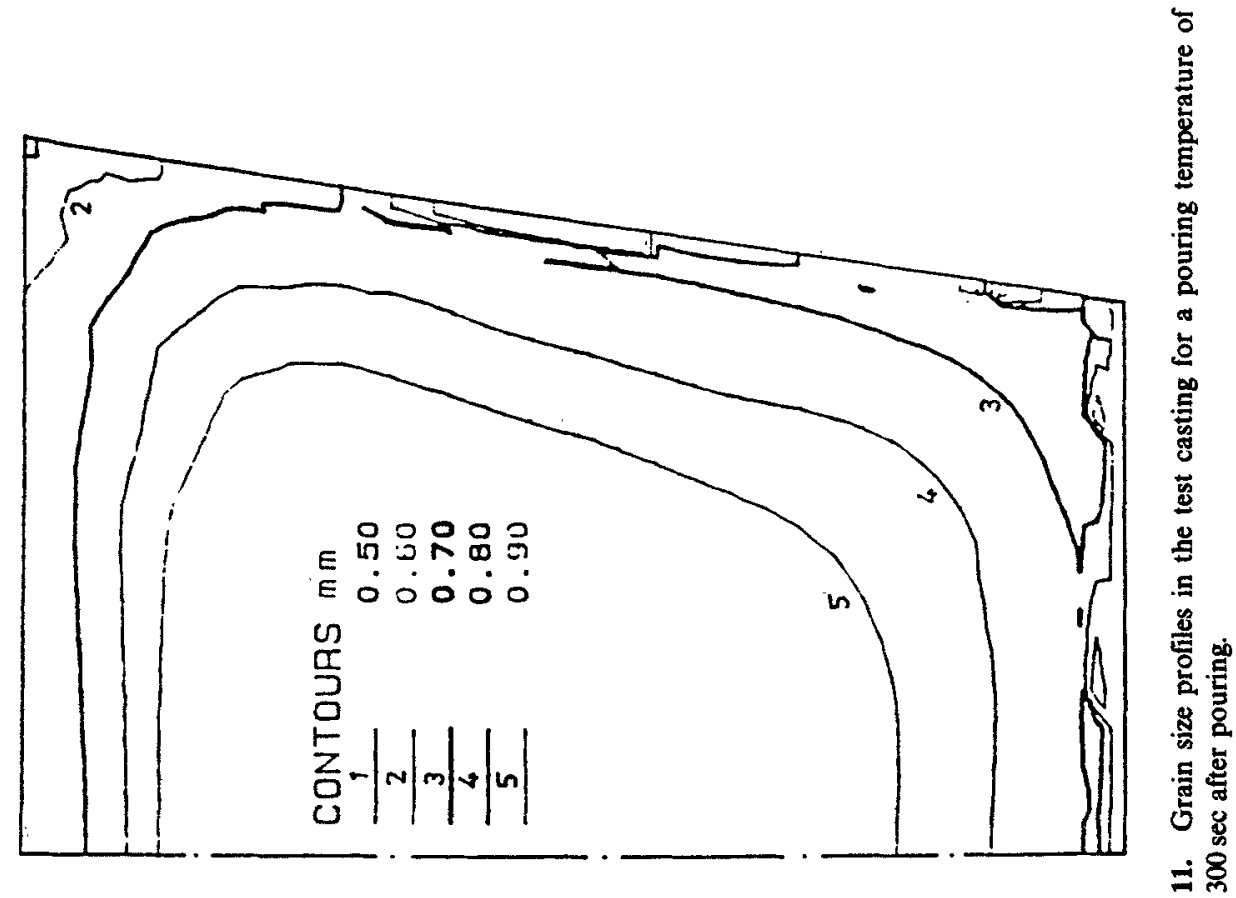

器

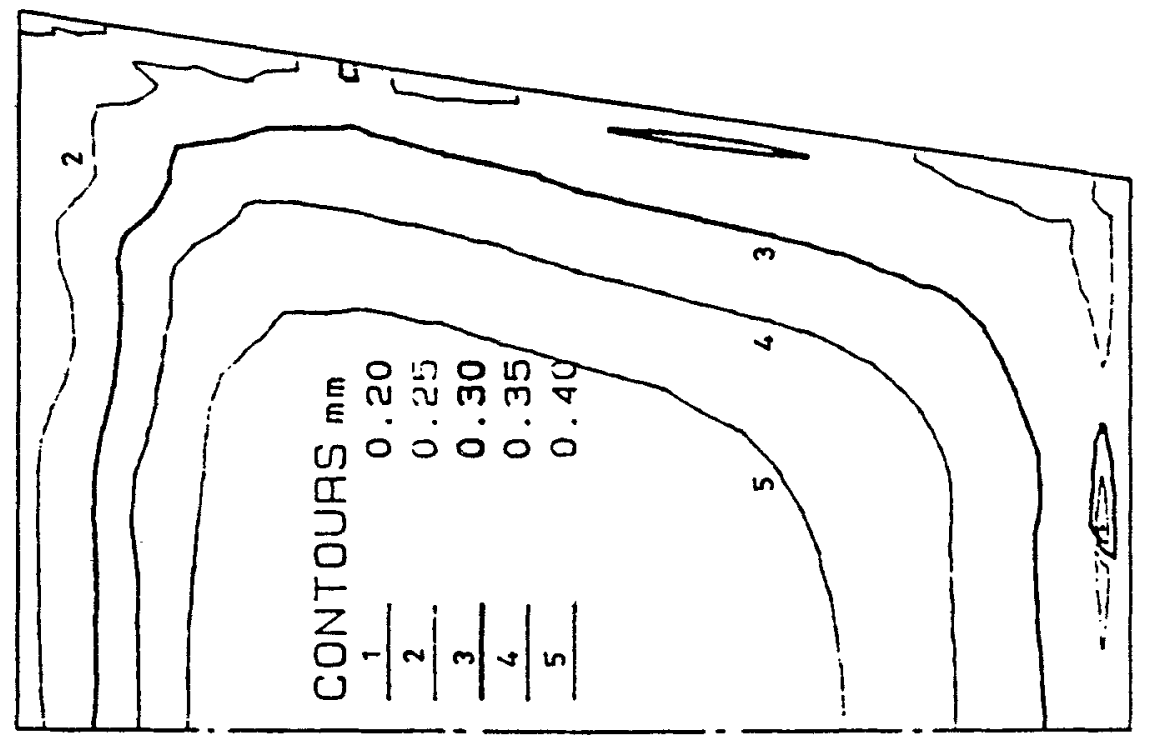

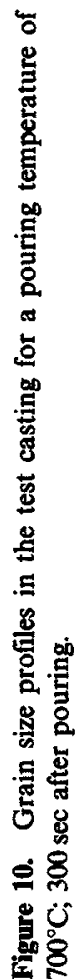




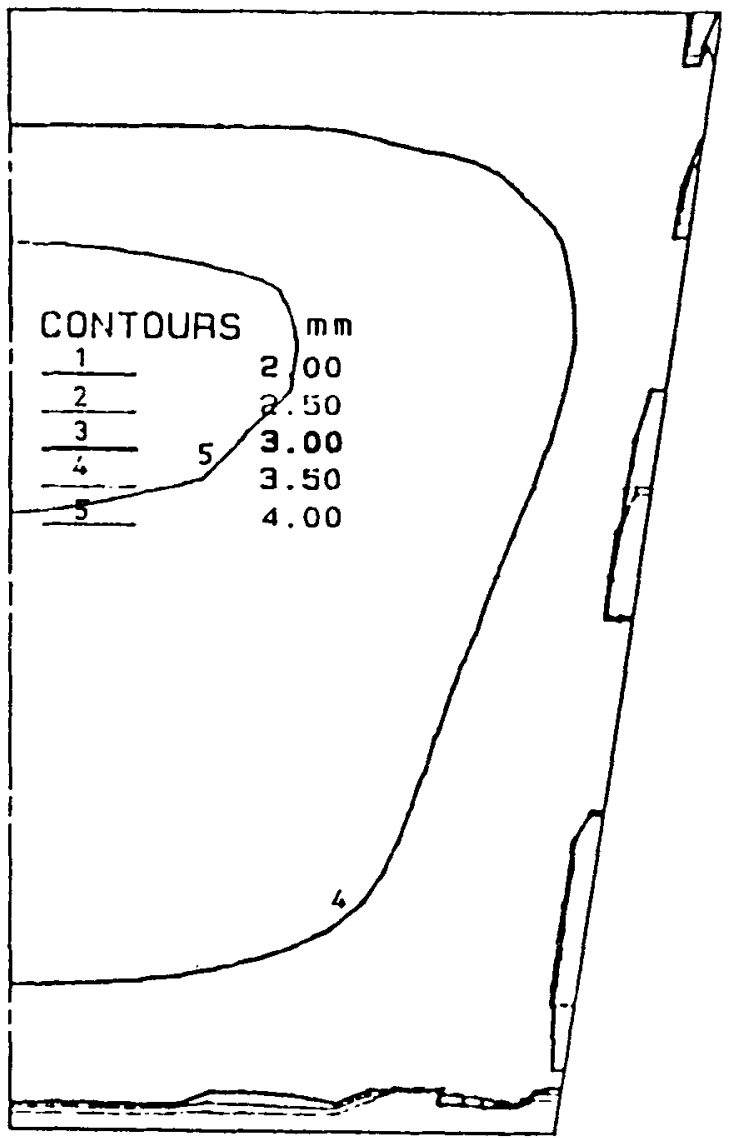

Figure 12. Grain size profiles in the test casting for a pouring temperature of $900^{\circ} \mathrm{C} ; 300 \mathrm{sec}$ after pouring.

Table 6. Comparison of grain size.

\begin{tabular}{lcc}
\hline $\begin{array}{l}\text { Pouring } \\
\text { temperature }\left({ }^{\circ} \mathrm{C}\right)\end{array}$ & $\begin{array}{c}\text { Experimental } \\
\text { grain radius } \\
(\mathrm{mm})\end{array}$ & $\begin{array}{c}\text { Predicted grain } \\
\text { radius }(\mathrm{mm})\end{array}$ \\
\hline 700 & 0.3889 & 0.4018 \\
800 & 1.076 & 0.9439 \\
900 & 3.663 & 3.226 \\
\hline
\end{tabular}

Table 7. Comparison of local times of solidification and dendritic arm spacings.

\begin{tabular}{lccccc}
\hline & \multicolumn{2}{c}{ Local time of solidification $(\mathrm{sec})$} & & \multicolumn{2}{c}{ Dendritic arm spacing $(\mu \mathrm{m})$} \\
\cline { 6 - 6 } \cline { 5 - 6 } $\begin{array}{l}\text { Pouring } \\
\text { temperature }\left({ }^{\circ} \mathrm{C}\right)\end{array}$ & Predicted & Simulated & & Predicted & Simulated \\
\hline 700 & 242.0 & 331.0 & & 54.8 & 62.5 \\
800 & 300.5 & 386.0 & & 58.9 & 66.7 \\
900 & 425.0 & 413.0 & & 66.1 & 71.4 \\
\hline
\end{tabular}


in a given casting observed were very narrow. In all the figures, larger grain radii are observed close to the centre of the casting as expected. However, some spurious high values of grain radii are also seen very close to the mould walls. This numerical error is introduced at the initial stages due to the numerical oscillations experienced close to the interface. All dimensions of the grain size contours shown in figures 10 to 12 are in $\mathrm{mm}$. Results shown correspond to $300 \mathrm{sec}$ after the start of solidification. The predicted and the experimentally determined grain radius values for each of the three pouring temperatures corresponding to the thermocouple location are given in table 6.

5.2d Local solidification times and dendritic arm spacings: The local solidification times and the dendritic arm spacings predicted by the macro-micro modelling are provided in table 7 along with the experimental values. It can be seen that the experimental and the simulated values agree well.

\section{Summary}

While the macro-micro model developed by Rappaz (1989) is very useful for predicting the microstructure in cast alloys, it does not take into account the effect of melt superheat. In the present analysis, the authors have suggested a mechanism of including melt superheat into account to estimate the grain size through modelling.

\section{Acknowledgements}

The authors wish to acknowledge the financial assistance given by the Department of Science and Technology, New Delhi, by sponsoring project No. III-4(2)/89-ET on CAD of Castings (Phase II) and Modelling of Metallurgical Microstructures.

\section{References}

Braaten M E 1985 Development and evaluation of iterative and direct method for the solution of equations governing recirculative flows, $\mathrm{Ph} \mathrm{D}$ Dissertation, University of Minnesota, Minnesota, USA

Bradley F J and Fung C A 1990 Proc. of F Weinberg int. symp. on solidification processing (eds) J E Lait and I V Samarasekera (London!. Pergamon Press) p. 333

Brown S G R and Spittle J A 1991 in Modelling of casting, welding and advanced solidification processes (Warrendale, PA: TMS) p. 395

Burden M H and Hunt J D 1974 J. Cryst. Growth 22 99, 109

Campbell J 1991 Mater. Sci. Technol. 7885

Cole G S and Bolling G F 1972 AFS Trans. 80211

Comini G and Del Giudice S 1985 Num. Heat Trans. 8133

Crivelli L A and Idelsohn S R 1986 Int. J. Numer. Meth. Eng. 2399

Dalhuijsen A J and Segal A 1986 Int. J. Numer. Meth. Eng. 231807

Daming Xu and Qingchun Li 1990 Num. Heat Trans. A20 203

Flood S C and Hunt J D 1987 J. Cryst. Growth 82 543, 552

Gandin Ch -A, Rappaz M and Tintillier R 1993 Met. Trans. A A24 467

Grest G S, Anderson M P and Srolovitz D J 1986 in Computer simulation of microstructural evolution (ed.) D J Srolovitz (Warrendale, PA: TMS) p. 21

Harlow F H and Welch J E 1965 Phys. Fluids 82182

Hirt C W, Nichols B D and Romero N C 1980 SOLA - A numerical solution algorithm for transient fluid flows (Los Alamos: Los Alamos Scientific Laboratory)

Hirt C W and Nichols B D 1981 J. Comput. Phys. 39201 
Hughes T J R 1978 Int. J. Numer. Meth. Eng. 121359

Hwang W S and Stoehr R A $1983 J$. Metals 3522

Jaisuk Yoo and Rubinsky B 1986 Int. J. Numer. Meth. Eng. 231785

Kannan K S, Madhusudana K, Venkataramani R, Ganesh N and Prabhakar O 1990 Indian J. Technol. 28460

Mackinnon R J and Carey G F 1987 Int. J. Numer. Meth. Eng. 24393

Madhusudana K, Venkataramani $R$ and Prabhakar O 1989 Solidification simulation-CADCAST, User Manual, DST Project No. III-4(38)/85-ET, IIT, Madras

Madhusudana K 1993 Finite element analysis of solidification in castings, $\mathrm{Ph} \mathrm{D}$ thesis, IIT, Madras

Morgan K, Lewis R W and Zienkiewicz O C 1978 Int. J. Numer. Meth. Eng. 121191

Narayanaprabhu K. Prasannakumar T S and Ramachandran T 1989 in Principles of solidification and materials processing (eds) $R$ Trivedi et al 2 p. 761

Ohnaka I 1990 Int. conf. on CAMSE-90(Computer applications to materials science and engineering), Tokyo, 8

Oldfield W 1966 Trans. ASM 59945

Patankar S V 1980 Numerical heat transfer and fluid flow (New York: Hemisphere Publishing Company)

Ramachandran N, Gupta J P and Jaluria Y 1982 Int. J. Heat Mass Trans. 25187

Rappaz M 1989 Int. Mater. Rev. 393

Rappaz M and Gandin Ch-A 1993 Acta Metall. 41345

Rolph III W D and Bathe K J 1982 Int. J. Numer. Meth. Eng. 18119

Salcudean M and Guthrie R I L 1979 Met. Trans. AIME B10 423

Samonds M, Lewis R W, Morgan K and Symberlist R 1985 in Computational techniques in heat transfer (eds) R W Lewis, K Morgan, S Johnson and W R Smith (Swansea: Pineridge Press) 1

Sharma D G R and Prabhakar O 1990 Report No. III-4(39)/85-ET, DST, New Delhi

Smith T G and Wilkes J O 1975 Comput. Fluids 51

Srinivasan M N 1982 Indian J. Technol. 20123

Stefanescu D M, Upadhya G and Bandhyopadhyay D 1990 Met. Trans. A A21 997

Venkataramani R, Gowrishankar N and Prabhakar O 1992 Met. Mater. Process. 4151

Voller V R, Cross M ard Markatose N C 1987 Int. J. Numer. Meth. Eng. 24271

Voller V R and Prakash C 1987 Int. J. Heat Mass Transfer 301709

Voller V R and Swaminathan C R 1990 Int. J. Numer. Meth. Eng. 30875

Zhu P and Smith W 1992 Acta Metall. 40683

\section{Nomenclature}

$\begin{array}{ll}u, v & \text { velocity components in } x \text { and } y \text { directions } \\ K & \text { permeability } \\ \mu & \text { dynamic viscosity } \\ p & \text { pressure } \\ S_{x}, S_{y} & \text { source terms in Navier-Stokes equation } \\ f_{l} & \text { fraction liquid } \\ R & \text { resistance function } \\ \Delta H(t) & \text { change in enthalpy as a function of time } \\ C_{1}, C_{2}, C, D & \text { constants } \\ N_{\max } & \text { maximum number of nuclei per unit volume } \\ R_{g} & \text { grain radius } \\ T_{\text {pour }} & \text { pouring temperature } \\ \Delta T_{\max } & \text { undercooling corresponding to the maximum of } \mathrm{d} N / \mathrm{d} \Delta T \\ N_{\text {act }} & \text { actual number of nuclei present per unit volume } \\ \Delta T_{\text {act }} & \text { actual maximum undercooling experienced } \\ \Delta T_{\sigma} & \text { range in the gaussian curve } \\ \Delta T & \text { undercooling }\end{array}$

